\title{
GC-MS PROFILE OF IN VIVO AND IN VITRO SHOOTS OF CLEOME GYNANDRA L.
}

\author{
KARTHIKEYAN A. V. P., SUDAN I. \\ P. G. and Research Department of Botany, Government Arts College (Autonomous), Karur 630005 \\ Email: avpkarthi1974@gmail.com
}

Received: 29 Jun 2017 Revised and Accepted: 21 Sep 2017

\begin{abstract}
Objective: Investigation of the bioactive compounds from the ethanol shoot extracts of in vivo and in vitro plants of Cleome gynandra (C. gynandra) through GC-MS analysis.

Methods: The nodal explants were cultured on Murashige and Skoog (MS) medium supplemented with different concentrations of 6-benzylaminopurine (BAP), kinetin-6-furfurylaminopurine (Kin) and indole 3 acetic acids (IAA) for shoot induction. In the present study, the phytochemical constituents were analyzed from the ethanol extract of in vivo and in vitro plants of C. gynandra using Gas Chromatography-Mass Spectrometry (GCMS) analysis. The mass spectrum of the ethanol extract was compared with the available library sources.

Results: In the present study, different concentrations of cytokinins and in the combination of IAA are used to develop regenerated shoots. The maximum number of shoots was obtained $9.2 \pm 0.41$ with the length of $6.6 \mathrm{~cm}$ and highest frequency of $(100 \%)$ shoot induction was observed on MS medium containing $10 \mu \mathrm{M}$ BAP with $4 \mu \mathrm{M}$ IAA. The GC-MS analysis revealed that the shoots of in vivo and in vitro plants contained 21phytochemicals, of these 3 components were similar in both in vivo and in vitro plants, 2 phytochemical's are repeated with different RT, 7 components are having biological activity and in the remaining 9 components, biological activities are not reported.
\end{abstract}

Conclusion: The present study, the in vitro regeneration, combinations of hormones (10 $\mu \mathrm{M}$ BAP plus $4 \mu \mathrm{M} \mathrm{IAA})$ tested showed the best result than individual and also revealed that the synthesis of more number of phytochemicals present in the ethanolic extracts of in vitro plants than the in vivo plants of C. gynandra.

Keywords: GC-MS, C. gynandra, In vivo and in vitro plants, Biological activity

(C) 2017 The Authors. Published by Innovare Academic Sciences Pvt Ltd. This is an open access article under the CC BY license (http://creativecommons.org/licenses/by/4.0/) DOI: http://dx.doi.org/10.22159/ijpps.2017v9i11.17351

\section{INTRODUCTION}

C. gynandra L. is commonly known as Cat whiskers, Spider flower and Nalvelai in Tamil. C. gynandra is used as a medicinal plant and can be found in all over the world [1]. It grows as a weed in paddy fields, roadsides and in open grasslands. In India, it is not at all cultivated but grows unexpectedly all over the place. Different species of Cleome can be found in all the states of India [2]. According to the Indian traditional system of Ayurveda medicine, lays prominent on the promotion of health concept of strengthening host defenses against different diseases [3]. In the literature of Pharmacopeia of India and also in other ancient medical texts it is described that the medicinal application of C. gynandra is an important medicinal plant in Ayurveda [4]. The plant's nutritional value may vary with soil fertility, environment, plant type, plant age and the production techniques used [5]

Plant tissue culture has been a preferred biotechnology for applications regarding medicinal plants for many years [6]. According to Alferman et al. [7], many attempts have been made to use plant cell culture for commercial production of plant secondary metabolites; In addition, Preil [8], blamed the lack of progress specifically on the high cost of bioreactors, slow growth of plants, and low yields of active metabolites. Plant tissue culture is one of the most useful methods for conservation and mass propagation of medicinal plants [9]. Medicinal plants have two types of metabolites; one of them is primary and another is secondary metabolites. Primary metabolites are directly involved in plant activities whereas secondary are not directly involved [10]. Development of in vitro procedures will help to establish tissues for germplasm conservation, rapid propagation and for secondary metabolite production to meet the vastly increased demand of therapeutic and other industries [11].

Phytochemical studies of $C$. gynandra have shown antimicrobial activity due to their bioactive constituents such as tannins, flavonoids, alkaloids and saponins [12-15]. The medicinal actions of particular plant species depend upon the secondary metabolites [1618]. Screening of the bioactive constituents leads to the development of new novel drugs for curing various maladies [19]. To the best of our knowledge and literature survey works on GC-MS analysis of $C$. gynandra is lacking. Hence the present study aims to explore the phytochemical constituents present in the ethanolic shoot extract of in vivo and in vitro plants of $C$. gynandra by GC-MS technique.

\section{MATERIALS AND METHODS}

Chemicals and reagents

All the solvents and other reagents used in the present study are of analytical grade and purchased from Himedia laboratories, India.

\section{Plant material and establishment of explants}

The plant material C. gynandra was collected from Arugampalayam, near Thanthonimalai, Karur of Tamil Nadu, India. The nodal segments with shoot tips were selected for the source of explants in the present study. The explant of nodal segments was excised and washed with running tap water for $30 \mathrm{~min}$ and followed by liquid detergent (Teepol) for $5 \mathrm{~min}$ for surface sterilization. They were rinsed with distilled water for 2-3 times to remove all the surface sterilizing agents. The surface sterilized materials were kept inside the laminar air flow chamber, where they were disinfected with $70 \%$ alcohol for 45 seconds followed by $0.1 \%$ mercuric chloride for 3 min. Finally, the material was thoroughly rinsed with sterile double distilled water for 4-5 times to remove all the sterilizing agents.

\section{Procedure for preparing culture media}

MS media was used as the basal medium with $3 \%$ of sucrose and respective growth regulators for shoot induction and multiplication. The medium was solidified with $0.8 \%$ of agar and the $\mathrm{pH}$ of the medium was adjusted to 5.8 using $0.1 \mathrm{~N} \mathrm{HCl}$ or $\mathrm{NaOH}$. The culture 
media were sterilized by autoclaving at $1.06 \mathrm{~kg} \mathrm{~cm}^{-3}$ and $121^{\circ} \mathrm{C}$ for 15-18 $\min [20]$

\section{Plant growth regulators}

MS medium containing different concentrations of Kin (5-25 $\mu \mathrm{M})$, BAP $(5-25 \mu \mathrm{M})$ either alone or in combination with IAA $(2-10 \mu \mathrm{M})$ were utilized for shoot induction and multiplication from nodal explants segments. Each experiment comprises of a minimum of 50 cultures and the experiments were repeated at least twice. The cultures were maintained in a culture room at $25 \pm 2{ }^{\circ} \mathrm{C}$ under $16 \mathrm{hr}$ photoperiod with a light intensity of $30-40 \mu \mathrm{M} \mathrm{mm}^{-2} \mathrm{~s}^{-1}$ supplied by cool white fluorescent tubes. The relative humidity (RH) within the culture room was maintained at $55 \pm 5 \%$. The media was refreshed at $4 \mathrm{~W}$ intervals.

\section{Statistical analysis}

The design of all the experiments was a randomized complete block design and each experiment consisted of ten tubes with one explant in each and ten replicates. The parameters recorded were the number of shoots per explant, shoot length and number of shoots.

\section{Extraction of samples for GC-MS analysis}

The in vivo and in vitro shoots were cleaned, shade dried and powdered in a mechanical grinder. $6 \mathrm{~g}$ of dry powder of each plant was soaked in $60 \mathrm{ml}$ ethanol [21]. The flask was shaken, this process repeated for $3 \mathrm{~d}$. Then it was filtered and evaporated at room temperature. Now the prepared sample is subjected to analysis [22].

\section{Gas chromatography-mass spectrometry analysis}

The GC-MS analysis of in vivo and in vitro plants of ethanol extracts of $C$. gynandra were performed using a GC-MS (Model; Thermo GCTrace Ultra) equipped with a VF $5 \mathrm{~ms}$ fused silica capillary column of $30 \mathrm{~m}$ length, diameter $0.25 \mu \mathrm{m}$ film thickness. Injection temperature was set at $260^{\circ} \mathrm{C}$. The oven temperature was programmed from 70 ${ }^{\circ} \mathrm{C}$ with the increase of $6{ }^{\circ} \mathrm{C} / \mathrm{min}$-raised to $260{ }^{\circ} \mathrm{C}$. Ionization of the sample components was performed in electron impact mode (EI, 70 $\mathrm{eV}$ ). Helium (99.9995\% purity) was the carrier gas fixed with a flow rate of $1.0 \mathrm{ml} \mathrm{min}^{-1}$. The mass range from $40-1000 \mathrm{~m} / \mathrm{z}$ was scanned at a rate of $3.0 \mathrm{scans} / \mathrm{s} 1.0 \mu \mathrm{l}$ of the ethanol extract of $C$. gynandra was injected with a Hamilton syringe to the GC-MS manually for total ion chromatographic analysis in split injection technique. Total running time of GC-MS is $30 \mathrm{~min}$. The relative percentage of each extract constituents was expressed as a percentage with pack area normalization.

\section{Identification of components}

The relative percentage amount of each component was calculated by comparing its average peak area to the total area. The detection employed the NIST (National Institute of Standards and Technology) Ver.2.0-Year 2005 library. The compound prediction is based on Dr. Duke's Phytochemical and Ethnobotanical Databases by Dr. Jim Duke of the Agricultural Research Service/USDA. Interpretation of GC-MS was conducted using the database of NIST having more than 62,000 patterns. The spectrum of the unknown component was compared with the ADMET of the known components stored in the NIST library [23].

\section{RESULTS}

\section{Shoot induction and multiplication}

The nodal explants of $C$. gynandra were inoculated on MS medium supplemented with different concentrations of BAP and Kin ranging from 5 to $25 \mu \mathrm{M}$ alone or in combination with IAA for shoot bud induction (table 1; fig. 1). Among the two cytokinins tested, BAP was found to be induced the maximum number of shoots than Kin. The highest frequency of shoot induction $(100 \%)$, a maximum number of shoots (8.2) and the shoot length of $6.36 \mathrm{~cm}$ were observed on MS medium containing $10 \mu \mathrm{M}$ BAP. However, Kin has induced 5.25 shoots with the shoot length of $4.62 \mathrm{~cm}$ at $15 \mu \mathrm{M}$.

The optimum level of BAP $(10 \mu \mathrm{M})$ was further tested with different concentrations of IAA ranging from 2 to $10 \mu \mathrm{M}$. Among the combinations tested, a maximum number of shoots (9.2) with shoot length of 6.6. $\mathrm{cm}$ was obtained on MS medium supplemented with 10 $\mu \mathrm{M}$ BAP along with $4 \mu \mathrm{M}$ IAA.

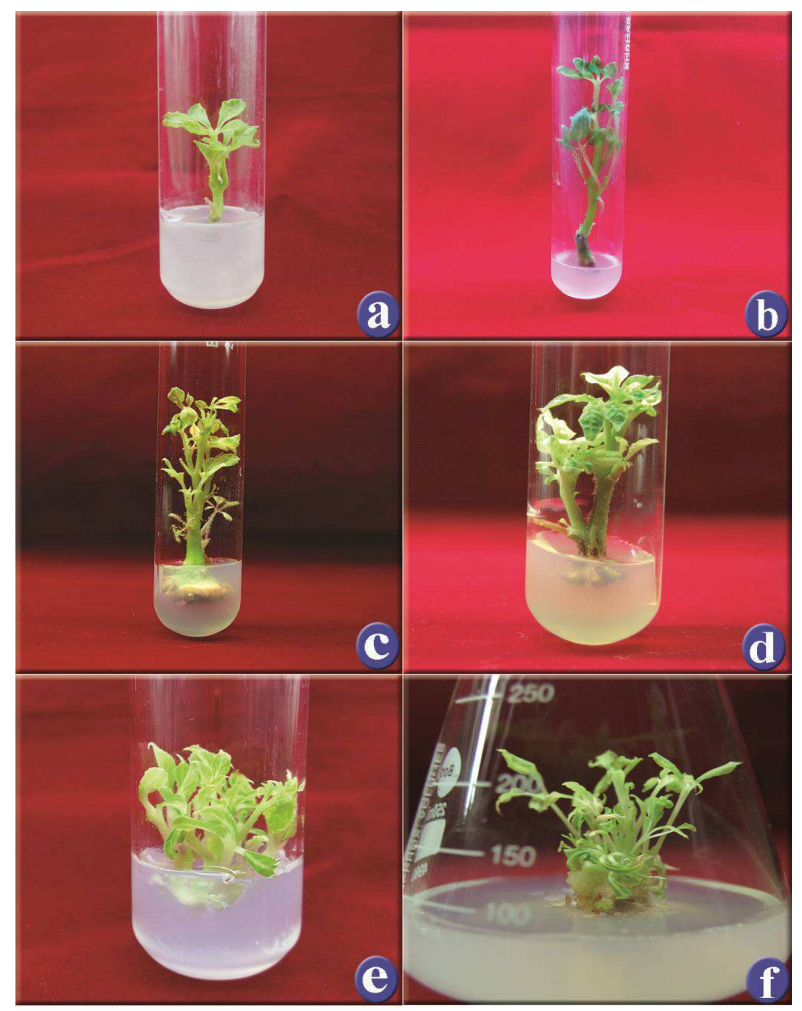

Fig. 1: In vitro regeneration of shoots from the nodal explants of $C$. gynandra a. Shoot initiation; $b$ and c. Shoot elongation; $d$, e and f. Shoot multiplication 
Table 1: Effect of different concentration of cytokinins and auxin on shoot induction and multiplication of C. gynandra from the nodal explants

\begin{tabular}{|c|c|c|c|c|c|}
\hline \multicolumn{2}{|c|}{ Concentration of cytokinins } & \multirow{2}{*}{$\begin{array}{l}\text { Concentration of auxin } \\
\text { IAA }\end{array}$} & \multirow[t]{2}{*}{ Shoot induction frequency (\%) } & \multirow[t]{2}{*}{ Number of shoots } & \multirow[t]{2}{*}{ Shoot length (cm) } \\
\hline BAP & Kin & & & & \\
\hline $5 \mu \mathrm{M}$ & --- & --- & 80.0 & $5.6 \pm 0.57$ & $4.86 \pm 1.37$ \\
\hline $10 \mu \mathrm{M}$ & --- & --- & 100 & $8.2 \pm 0.41$ & $6.36 \pm 1.66$ \\
\hline $15 \mu \mathrm{M}$ & -- & --- & 66.6 & $4.0 \pm 0.40$ & $4.24 \pm 0.65$ \\
\hline $20 \mu \mathrm{M}$ & -- & --- & 63.3 & $3.75 \pm 0.47$ & $4.28 \pm 0.88$ \\
\hline $25 \mu \mathrm{M}$ & --- & --- & 53.3 & $3.8 \pm 0.41$ & $3.64 \pm 1.21$ \\
\hline--- & $5 \mu \mathrm{M}$ & --- & 66.6 & $2.5 \pm 0.28$ & $4.14 \pm 0.98$ \\
\hline--- & $10 \mu \mathrm{M}$ & --- & 73.3 & $3.75 \pm 0.47$ & $5.66 \pm 1.50$ \\
\hline--- & $15 \mu \mathrm{M}$ & --- & 70 & $5.25 \pm 0.75$ & $4.62 \pm 0.62$ \\
\hline--- & $20 \mu \mathrm{M}$ & --- & 50 & $3.6 \pm 0.57$ & $3.88 \pm 1.06$ \\
\hline--- & $25 \mu \mathrm{M}$ & --- & 46.6 & $3.4 \pm 0.44$ & $2.82 \pm 1.02$ \\
\hline $10 \mu \mathrm{M}$ & --- & $2 \mu \mathrm{M}$ & 95 & $8.0 \pm 0.57$ & $5.86 \pm 1.37$ \\
\hline $10 \mu \mathrm{M}$ & --- & $4 \mu \mathrm{M}$ & 100 & $9.2 \pm 0.41$ & $6.6 \pm 1.66$ \\
\hline $10 \mu \mathrm{M}$ & --- & $6 \mu \mathrm{M}$ & 76.6 & $5.0 \pm 0.40$ & $4.74 \pm 0.65$ \\
\hline $10 \mu \mathrm{M}$ & --- & $8 \mu \mathrm{M}$ & 73.3 & $4.35 \pm 0.47$ & $4.68 \pm 0.88$ \\
\hline $10 \mu \mathrm{M}$ & --- & $10 \mu \mathrm{M}$ & 66.3 & $3.8 \pm 0.41$ & $4.02 \pm 1.21$ \\
\hline
\end{tabular}

Values are mean \pm SE. Ten replicates repeated 3 times recorded after $30 \mathrm{~d}$ of culture.

\section{Phytochemical analysis by GC-MS}

The GC-MS analysis revealed that various bioactive compounds were identified in the ethanol extract of in vivo and in vitro shoots of $C$. gynandra (table 2, fig. 2 and 3). The active principle components with their retention time (RT), molecular formula, molecular weight (MW) and concentration (\%) in the ethanol extract of in vivo and in vitro shoots were tabulated in table 2 .

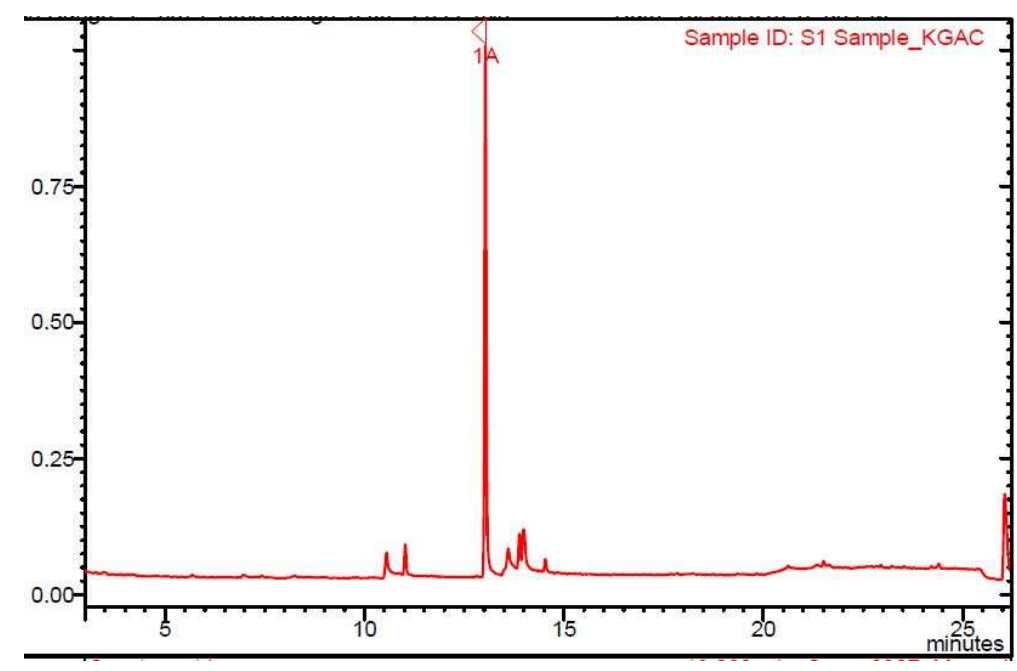

Fig. 2: GC-MS chromatogram of ethanol extract of in vivo shoots of $C$. Gynandra

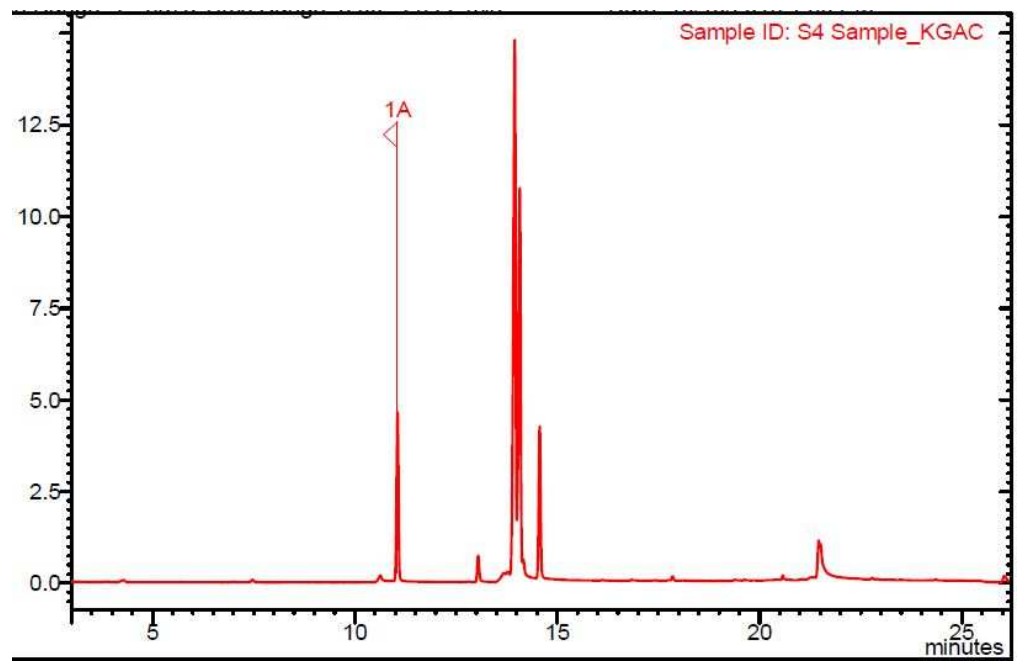

Fig. 3: GC-MS chromatogram of ethanol extract of in vitro shoots of $C$. Gynandra 
The mass spectrum of leaves of in vivo and in vitro plants revealed the presence of 21 phytochemicals. Of these 3 components were similar in both in vivo and in vitro plants. They are namely $\mathrm{n}$ hexadecanoic acid, hexadecanoic acid, ethyl ester, 3,7,11,15tetramethyl-2-hexadecen-1-ol but the RT is slightly increased in in vitro plants when compared to in vivo plants. 2 phytochemical's are repeated with different RT, namely 9,12,15-octadecatrienal and eicosanoic acid ethyl ester. Among the 16 different phytochemicals, 7 components are having biological activity and in the remaining 9 components the activities are not reported (table 3 ).

The shoots of ethanolic extracts of in vivo plants showed 10 different phytochemicals. They are n-hexadecanoic acid, hexadecanoic acid, ethyl ester, 3,7,11,15-tetramethyl-2-hexadecen-1-ol, 9-octadecynoic acid, 9,12,15-octadecatrienal, 8,11,14-eicosatrienoic acid, methyl ester, (Z,Z,Z), acetamide, N-methyl-N-[4-(3-hydroxypyrrolidinyl)-2butynyl], 1-hexadecanol, 2-methyl, methylene chloride. Similarly, the shoots of ethanolic extracts of in vitro plants showed 11 different components.

They are acetic acid, 3-cyano-2-cyclohexyl-[1,2]oxazinan-6-ylmethyl ester, eicosanoic acid, ethyl ester, n-hexadecanoic acid, hexadecanoic acid, ethyl ester, 3,7,11,15-tetramethyl-2-hexadecen-1-ol, Ethyl 9. cis.,11. Trans.-octadecadienoate, (E)-9-octadecenoic acid ethyl ester, eicosanoic acid, ethyl ester, ethyl 14-methyl-hexadecanoate, docosanoic acid, ethyl ester, 2-methyl-Z, Z-3,13-octadecadienol.

Table 2: Components detected in the in vivo and in vitro shoots in ethanol extract of $C$. gynandra

\begin{tabular}{|c|c|c|c|c|c|}
\hline \multirow[t]{2}{*}{ S. No. } & \multirow[t]{2}{*}{ R. T. } & \multirow[t]{2}{*}{ Name of the compound } & \multicolumn{2}{|c|}{ Peak area \% } & \multirow{2}{*}{$\begin{array}{l}\text { Molecular } \\
\text { Weight }\end{array}$} \\
\hline & & & $\begin{array}{l}\text { In vivo } \\
\text { plants }\end{array}$ & $\begin{array}{l}\text { In vitro } \\
\text { Plants }\end{array}$ & \\
\hline 1. & 10.587 & n-hexadecanoic acid & 4.080 & 0.52 & 256 \\
\hline 2. & 11.021 & Hexadecanoic acid, ethyl ester & 5.192 & 9.91 & 284 \\
\hline 3. & 13.021 & 3,7,11,15-tetramethyl-2-hexadecen-1-ol & 61.893 & 1.68 & 296 \\
\hline 4. & 13.645 & $9,12,15$-octadecatrienal & 7.036 & -- & 262 \\
\hline 5. & 13.867 & 9-octadecynoic acid & 0.084 & --- & 280 \\
\hline 6. & 13.931 & $9,12,15$-octadecatrienal & 15.777 & -- & 262 \\
\hline 7. & 14.561 & 8,11,14-Eicosatrienoic acid, methyl ester, (Z,Z,Z)- & 1.443 & -- & 320 \\
\hline 8. & 21.540 & Acetamide, N-methyl-N-[4-(3-hydroxypyrrolidinyl)-2-butynyl]- & 0.050 & -- & 210 \\
\hline 9. & 24.404 & 1-hexadecanol, 2-methyl- & 2.790 & -- & 256 \\
\hline 10. & 26.050 & methylene chloride & 0.054 & -- & 84 \\
\hline 11. & 4.529 & Acetic acid, 3-cyano-2-cyclohexyl-[1,2] oxazinan-6-ylmethyl ester & -- & 0.26 & 266 \\
\hline 12. & 7.475 & Eicosanoic acid, ethyl ester & -- & 0.21 & 340 \\
\hline 13. & 13.962 & Ethyl 9. cis.,11. trans.-octadecadienoate & -- & 35.424 & 308 \\
\hline 14. & 14.083 & (E)-9-octadecenoic acid ethyl ester & -- & 32.28 & 310 \\
\hline 15. & 14.563 & Eicosanoic acid, ethyl ester & -- & 9.52 & 340 \\
\hline 16. & 17.876 & Ethyl 14-methyl-hexadecanoate & -- & 0.49 & 298 \\
\hline 17. & 20.582 & Docosanoic acid, ethyl ester & -- & 0.41 & 368 \\
\hline 18. & 21.524 & 2-methyl-Z,Z-3,13-octadecadienol & -- & 6.84 & 280 \\
\hline
\end{tabular}

Table 3: Biological activity of phytochemical identified in the ethanol extracts of in vivo and in vitro shoots of $C$. gynandra

\begin{tabular}{|c|c|c|c|}
\hline $\begin{array}{l}\text { S. } \\
\text { No. }\end{array}$ & $\begin{array}{l}\text { Name of the } \\
\text { compound }\end{array}$ & Nature of compound & Biological activity \\
\hline 1. & n-hexadecanoic acid & Palmitic acid & $\begin{array}{l}\text { Antioxidant, hypocholesterolemic } \\
\text { nematicide, pesticide, lubricant, } \\
\text { antiandrogenic, flavor, hemolytic, 5-alpha-reductase } \\
\text { inhibitor }\end{array}$ \\
\hline 2. & Hexadecanoic acid, ethyl ester & Palmitic acid ester & $\begin{array}{l}\text { Antioxidant, hypocholesterolemic } \\
\text { nematicide, pesticide, lubricant, } \\
\text { antiandrogenic, flavor, hemolytic 5-alpha reductase } \\
\text { inhibitor }\end{array}$ \\
\hline 3. & 3,7,11,15-tetramethyl-2-hexadecen-1-ol & Terpene alcohol & Antimicrobial, anti-inflammatory \\
\hline 4. & $9,12,15$-octadecatrienal & Linoleic acid & $\begin{array}{l}\text { Cancer preventive, hypocholesterolemic, anti } \\
\text { coronary activity }\end{array}$ \\
\hline 5. & 11,14,17-eicosatrienoic acid, methyl ester & $\begin{array}{l}\text { Unsaturated fatty acid } \\
\text { ester }\end{array}$ & Antiarthritic, anti-coronary Anti-inflammatory \\
\hline 6. & 9-octadecenoic acid (Z) ethyl ester & Fatty acid ethyl ester & Steroids and primer pheromone \\
\hline 7. & 8,11,14-eicosatrienoic acid, methyl ester, $(\mathrm{Z}, \mathrm{Z}, \mathrm{Z})$ - & Ester compound & No activity reported \\
\hline 8. & $\begin{array}{l}\text { Acetamide, N-methyl-N-[4-(3-hydroxypyrrolidinyl)-2- } \\
\text { butynyl]- }\end{array}$ & Alcoholic compound & No activity reported \\
\hline 9. & 1-hexadecanol, 2-methyl- & Alcoholic compound & No activity reported \\
\hline 10. & Methylene chloride & Acetic compound. & No activity reported \\
\hline 11. & $\begin{array}{l}\text { Acetic acid, 3-cyano-2-cyclohexyl-[1,2]oxazinan-6- } \\
\text { ylmethyl ester }\end{array}$ & Ester compound. & No activity reported \\
\hline 12. & Ethyl 9. cis.,11. trans.-octadecadienoate & Bronsted acid & No activity reported \\
\hline 13. & (E)-9-octadecenoic acid ethyl ester & Ester compound & Antioxidant, anti-inflammatory \\
\hline 14. & Eicosanoic acid, ethyl ester & Ester compound & No activity reported \\
\hline 15. & Ethyl 14-methyl-hexadecane & Alcoholic compound & No activity reported \\
\hline 16. & Docosanoic acid, ethyl ester & Ester compound & No activity reported \\
\hline
\end{tabular}




\section{DISCUSSION}

Micropropagation techniques allow being created millions of genetically identical plants. Several plant growth regulators are available for shoot induction and multiplication. However, BAP, Kin, thidiazuron (TDZ) and Isopentenyl adenine (2-iP) are widely used. In the present study, BAP and Kin are used individually or in the combination of both. As far as the individual hormone concerned 10 $\mu \mathrm{M}$ BAP was found to be the optimum concentration for shoot multiplication from the nodal explants. Similar results are also reported in several plants such as Mentha piperita [24], Swertia chirayita [25], Andrographis paniculata [26], Sarcostemma brevistigma [27]. The results are in agreement with earlier findings as observed in Sesamum indicum [28], Enicostema axillare [29], same as the concentration [30], whereas, the combination of $10 \mu \mathrm{M}$ BAP plus $4 \mu \mathrm{M}$ IAA increases the shoot induction and more number of shoots. The results also are in agreement with earlier findings as observed in Mentha viridis [31], Bacopa monneiri [32], Lobelia nicotianaefolia [33] and Solanum nigrum [34] where BAP and KIN resulted in marked increase in shoot multiplication.

For the detection and identification of plant metabolites analysis, a new discipline known as plant metabolites developed. Metabolite profiling and metabolite fingerprinting are recently developing technology for phenotypic diagnosis of plant analysis [35-36]. They help us for the identification of most important compounds (or groups of compounds) present between genotypes or phenotypes.

For in vivo and in vitro plant, n-hexadecanoic acid was identified as the first component with the RT of $10.587 \mathrm{~min}$. This compound has the molecular formula of $\mathrm{C}_{16} \mathrm{H}_{32} \mathrm{O}_{2}$ and comprised in in vivo plants in $4.08 \%$ and in vitro plants in $0.52 \%$ of the ethanolic shoots extract of C. gynandra (table 2). It may have the role of antioxidant, hypocholesterolemic, nematicide, pesticide, lubricant, antiandrogenic (table 3) [37-38].

The 3,7,11,15-tetramethyl-2-hexadecen-1-ol $\left(\mathrm{C}_{20} \mathrm{H}_{40} \mathrm{O}\right)$ also called as phytol was the second compound having a molecular weight of 296 with the RT of $13.021 \mathrm{~min}$. It was present in in vivo plant in 61.893\% and an in vitro plant in $1.68 \%$ this compound has antimicrobial and anti-inflammatory activity [39-40]. The third compound was (E)-9octadecenoic acid ethyl ester $\left(\mathrm{C}_{20} \mathrm{H}_{38} \mathrm{O}_{2}\right)$ which was determined at the RT of $13.867 \mathrm{~min}$ and it has the molecular weight of 280 (table 2). This compound was absent in in vitro regenerated shoots of $C$. gynandra and it has the property of antimicrobial and antiinflammatory activity (table 3) [34-36]. 9,12,15-octadecatrienal is also one of the chemical constituents that were identified from plantlets. It is a linoleic acid $\left(\mathrm{C}_{18} \mathrm{H}_{30} \mathrm{O}\right)$ present in the $\mathrm{RT}$ of 13.645 min (table 2). It has a molecular weight of 262, and it has antiinflammatory, hypocholesterolemic, cancer preventive [41-42] hepatoprotective, nematicide, insectifuge, antihistaminic, antieczemic, antiacne, 5-alpha-reductase inhibitor, anti-androgenic, antiarthritic, anti-coronary and insecticidal activity [43-45].

The compound (E)-9-octadecenoic acid ethyl ester was present only in in vitro regenerated shoots of C. gynandra with the RT of 14.083 and has a molecular weight of 310 . It was an ester compound and has an antioxidant, anti-inflammatory activity. The percentage of the peak area was $32.28 \%[46]$.

\section{CONCLUSION}

In vitro regeneration system provides disease-free plant material that is free from external contamination. In the present study, nodal explants were cultured on MS medium fortified with various concentrations of BAP or Kin. BAP was comparatively better than Kin for shoot regeneration. The addition of IAA along with BAP significantly increased the number of shoots per explant and average shoot length. This protocol could be used for large-scale production of this important medicinal plant. The in vitro regenerated shoots and in vivo shoots were further investigated for the presence of phytochemical constituents through GC MS. From the GC-MS study, 16 different compounds have been identified from the ethanol extract of in vivo and in vitro shoots of $C$. gynandra. Therefore the presence of various bioactive compounds in the plants of $C$. gynandra justifies the use of the plant in the treatment of different ailments by the traditional practitioners and it further holds promise for the production of novel pharmaceuticals.

\section{ACKNOWLEDGEMENT}

The authors wish to thank the University Grants Commission, New Delhi for providing financial assistance to carry out the Major Research Project on Cleome gynandra L. (F. No.: 43-143/2014(SR) dated 21.07.2015, University Grants Commission, New Delhi).

\section{AUTHORS CONTRIBUTION}

Most of the experimental part of the work was done by the Research scholar I. Sudan. Dr. A. V. P. Karthikeyan, Guide and Principal Investigator of the UGC project, guided and monitored the experimental design, data compilation, and statistical analysis and corrected the manuscript.

\section{CONFLICT OF INTERESTS}

The authors do not have any conflict of interest to declare.

\section{REFERENCES}

1. Kuhn U. Capparaceae in Dicot Weed. TJ Hafliger, M Wolf. eds. CIBA Geigy LTD, Basle, Switzerland; 1988. p. 109-20.

2. Karthikeyan AVP, Shanmuganathan T, Karthi C. In vitro propagation of Cleome gynandra L. through direct organogenesis. Int J Sci Res 2014;3:1368-72.

3. Shanmuganathan T, Karthikeyan AVP. Antimicrobial activity of in vivo and in vitro plants of Cleome gynandra $\mathrm{L}$. World J Pharm Pharm Sci 2016;5:948-53.

4. Ammara H, Salma R, Farah D, Shahid M. Antimicrobial activity of some plant extracts having hepatoprotective effects. J Med Plant Res 2009;3:20-3.

5. Chweya JA. Genetic enhancement of indigenous vegetables in Kenya. Paper presented at the workshop 'Genetic Resources of Traditional Vegetables in Africa: Options for Conservation and Use. Nairobi Kenya 1995;8:29-31.

6. Babu KN, Minoo D, Geetha SP, Sumanthi V, Praveen K. Biotechnology of turmeric and related species. In: PN Ravindran, KN Babu, K Sivaraman. Eds. Turmeric: The genus Curcuma CRC Press: Boca Raton; 2007. p. 107-27.

7. Alfermann A, Petersen M, Fuss E. Production of natural products by plant cell biotechnology: results, problems and perspectives. In: M Lamier, W Rucker. Eds. Plant Tissue Culture 100 Y Since Gottlieb Haberlandt. Springer, New York; 2003. p. 153-66.

8. Preil W. A personal reflection on the use of liquid media for in vitro culture. In: A Hvoslef-Eide, W Preil. Eds. Liquid systems for in vitro plant propagation. Springer, Dordecht; 2005. p. 118.

9. Mary Sujin R, John De Britto A. Conservation of Vitex trifolia L. through in vitro Micropropagation. Int J Appl Biores 2013;15:35-8.

10. Aanchal Jain, Shashank Bhatt, Suresh Dhyani. Phytochemical screening of secondary metabolites of Ziziphus mauritiana Lam. Bark. Int J Curr Pharm Res 2012;4:156-9.

11. Nesy EA, Jose Padikkala, Lizzy Mathew, In vitro plant regeneration of Thevetia neriifolia Juss. from internode explants via indirect organogenesis. Int J Pharm Pharm Sci 2015;7:169-72.

12. Chukwuka KS, Ikheloa JO, Okonko IO, Moody JO, Mankinde TA. The antimicrobial activities of some medicinal plants on Escherichia coli as the agent of diarrhea in livestock. Adv Appl Sci Res 2011;2:37-48.

13. Bala A, Haldar PK, Kar B, Naskar S, Saha P, Kundusen S, et al. Antioxidant activity of the fractions of Cleome gynandra promotes antitumor activity in Ehrlich ascites Carcinoma. Asian J Chem 2011;23:5055-60.

14. Karimulla Shaika, Afsar Shaika, Deepak Kumar B, Devi Kadirvel. Evaluation of preliminary phytochemical properties and hypoglycemic activity of Cleome gynandra L. Int J Pharm Pharm Sci 2013;5:824-8.

15. Ajaiyeoba EO. Phytochemical and antimicrobial studies of Gynandropsis gynandra and Buchholzia coriaceae extracts. Afr J Biomed 2000;3:161-5. 
16. Meda NTR, Bangou MJ, Bakasso S, Millogo-Rasolodimby J, Nacoulma OG. Antioxidant activity of phenolic and flavonoid fractions of Cleome gynandra and Maerua angolensis of Burkina Faso. J Appl Pharma Sci 2013;3:36-42.

17. Shanmuganathan T, Karthikeyan AVP. Phytochemical analysis and antioxidant activities of in vivo and in vitro shoots of Cleome gynandra L. Int J Sci Res 2016;5:208-11.

18. Mule SN, Patil SB, Naikwade NS, Magdum CS. Evaluation of the antinociceptive and anti-inflammatory activity of stems of Gynandropsis pentaphylla Linn. Int J Green Pharm 2008;2:87-90.

19. Wink M. Introduction: biochemistry, role and biotechnology of secondary products in the biochemistry of secondary product metabolism. Ed. Wink M. CRC Press: Boca Raton, FL; 1999;1:16-20.

20. Murashige T, Skoog F. A revised medium for rapid growth and bioassay with tobacco tissue cultures. Physiol Plant 1962;15:473-97.

21. Muhammad Tayyab, Durre Shahwar. GC-MS analysis of Cannabis sativa L. from four different areas of Pakistan. Egyptian J Forensic Sci 2015;5:114-25.

22. Mooza Al-Owaisi, Nora Al-Hadiwi, Shah Alam Khan. GC-MS analysis, determination of total phenolics, flavonoid content and free radical scavenging activities of various crude extracts of Moringa peregrina (Forssk.) Fiori leaves. Asian Pac J Trop Biomed 2014;4:964-70.

23. Dr. Duke's Phytochemical and Ethnobotanical Databases. Available from: URL: http://www.ars-grin.gov/duke. [Last accessed on 20 Dec 2016].

24. Ghanti K, Kaviraj CP, Venugopal RB, Jabeen FTZ, Rao S. Rapid regeneration of Mentha piperita L. from shoot tip and nodal explants. Indian J Biotech 2004;3:594-8.

25. Joshi P, Dhawan V. Axillary multiplication of Swertia chirayita (Roxb. Ex Fleming) H. Karst., a critically endangered medicinal herb of temperate Himalayas. In Vitro Cell Dev Biol Plant 2007;43:631-8.

26. Purkayastha J, Sugla T, Paul A, Solleti S, Sahoo L. Rapid in vitro multiplication and plant regeneration from nodal explants of Andrographis paniculata: a valuable medicinal plant. In Vitro Cellular Dev Biol-Plant 2008;44:442-7.

27. Thomas TD, Shankar S. Multiple shoot induction and callus regeneration in Sarcostemma brevistigma Wight and Arnott, a rare medicinal plant. Plant Biotech Rep 2009;3:67-74.

28. Baskaran P, Jayabalan N. In vitro mass propagation and diverse callus orientation on Sesamum indicum L.-an important oil plant. J Agric Tech 2006;2:259-69.

29. Loganathan $K$, Narmatha Bai V. High frequency in vitro plantlet regeneration and antioxidant activity of Enicostema axillare (Lam.) Raynal ssp. littoralis (Blume) raynal an important medicinal plant. Asian Pacific J Repro 2014;3:241-8.
30. Shrivastava N, Rajani M. Multiple shoot regeneration and tissue culture studies on Bacopa monnieri (L.) Pennell. Plant Cell Rep 1999;18:919-23.

31. Rahman MM, Ankhi UR, Biswas A. Micropropagation of Mentha viridis L.: An aromatic medicinal plant. Int J Pharm Life Sci 2013;4:2926-30.

32. Chandra Gurnani, Vikram Kumar, Shinam Mukhija, Abha Dhingra, Sohan Rajpurohit, Poonam Narula. In vitro regeneration of Brahmi (Bacopa monneiri (l.) Penn.)-a threatened medicinal plant. Kathmandu University J Sci Eng Technol 2012;8:97-9.

33. Ganesan CM, Paulsamy S. Mass propagation of an economically important medical plant, Lobelia nicotianaefolia Heyne using in vitro culture technique. Nat Prod Int J 2102;8:35-40.

34. Bhat MA, Mujib A, Junaid A, Mohamooduafar M. In vitro regeneration of Solanum nigrum with enhanced solasodine production. Biol Plant 2010;4:757-60.

35. Krishnan P, Kruger NJ, Ratcliffe RG. Metabolite fingerprinting and profiling in plants using NMR. J Exp Bot 2004;56:255-65.

36. Schauer N, Fernie AR. Plant metabolomics: towards biological function and mechanism. Trends Plant Sci 2006;11:508-16.

37. Anbazhagi K, Kadavul G, Suguna A, Petrus JA. Studies on the pharmacognostical and in vitro antioxidant potential of Cleome gynandra Linn. Leaves. Natl Prod Radiance 2009;8:151-7.

38. Prameela J, Ramakrishnaiah H, Krishna V, Deepalakshmi AP. GC-MS analyses of leaf and root extracts of Didymocarpus tomentosa. Int J Pharm Pharm Sci 2015;7:423-5.

39. Ruthiran Papitha, Lokesh Ravi, Chinnadurai Immanuel Selvaraj. Phytochemical studies and GC-MS analysis of spermadictyon suaveolens roxb. Int J Pharm Pharm Sci 2017;9:143-9.

40. Maruthupandian A, Mohan VR. GC-MS analysis of some bioactive constituents of Pterocarpus marsupium Roxb. Int J Chem Tech Res 2011;3:1652-7.

41. Sermakkani M, Thangapandian V. GC-MS analysis of Cassia italica leaf methanol extract. Asian J Pharma Clin Res 2012;5:90-4.

42. Ashwani Kumar, Surender Singh, Sandeep Jai, Parvin Kumar. Synthesis antimicrobial evaluation, QSAR and in silico ADMET studies of decanoic acid derivatives. Acta Poloniae Pharm Drug Res 2011;68:191-204.

43. Raja Rajeswari N, Rama Lakshmi S, Muthuchelian K. GC-MS analysis of bioactive components from the ethanolic leaf extract of Canthium dicoccum (Gaertn.) Teijsm and Binn. J Chem Pharm Res 2011;3:792-8.

44. Hema R, Kumaravel S, Alagusundaram K. GC/MS determination of bioactive components of Murraya koenigii.J Am Sci 2011;7:80-3.

45. Srinivas R, Jyothi Chaitanya P, Chandrashekar R, Lakshmi Bhavani N. Analysis of preliminary phytochemicals of leaf extracts of Cleome gynandra L. World J Pharm Sci 2014;2:1043-5.

46. Syeda FA, Habib-Ur-Rehman, Choudhary MI, Atta-Ur-Rahman. GC-MS analysis of petroleum ether extract (oil) and bioassays of crude extract of Iris germanica. Int J Gen Mole Biol 2011;3:95-100 